\title{
Influência de ciclos molhagem-secagem em fibras de sisal sobre a aderência com matrizes de cimento Portland
}

\author{
Effect of sisal fiber hornification on the adhesion \\ with portland cement matrices
}

Ferreira, S.R. ${ }^{1}$; Lima, P.R.L. ${ }^{1}$; Silva, F.A. ${ }^{2}$; Toledo Filho, R.D. ${ }^{2}$

\begin{abstract}
${ }^{1}$ PPGECEA/UEFS Av. Transnordestina, s/n, Novo Horizonte, cep 44.036-900, Feira de Santana, BA. e-mail: ferreira.sr@hotmail.com; mailto:lima.prl@pq.cnpq.br

${ }^{2}$ Programa de Engenharia Civil /COPPE/UFRJ Caixa Postal 68506 - 21941-972, Rio de Janeiro, RJ. e-mail: fsilva@,coc.ufri.br ; toledo@coc.ufrj.br
\end{abstract}

\section{RESUMO}

Visando a redução da capacidade de absorção de água de fibras ligno-celulósicas, ciclos de molhagem e secagem são usualmente utilizados na indústria de papel e celulose. Esse procedimento enrijece a estrutura polimérica das fibro-células (processo conhecido como hornificação) resultando assim em maior estabilidade dimensional da fibra. No presente estudo foi avaliada a influência da hornificação de fibras de sisal no seu comportamento físico (variações dimensionais e absorção de água), mecânico (comportamento sob cargas de tração direta) e microestrutural (modificações superficiais da fibra e da estrutura das fibro-células). Ensaios de arrancamento da fibra de sisal em matriz de cimento portland foram realizados, utilizando comprimentos de embebimento de $25 \mathrm{~mm}$ e $50 \mathrm{~mm}$, com o objetivo de verificar se a possível estabilidade dimensional decorrente da hornificação aumentava a adesão fibra-matriz. Os resultados indicaram maior estabilidade dimensional, redução na capacidade de absorção de água, aumento na resistência à tração e capacidade de deformação e redução no módulo de elasticidade da fibra de sisal com a hornificação. Acréscimos na carga de arrancamento foram observados indicando uma maior aderência da fibra hornificada à matriz de cimento.

Palavras-chave: Fibras naturais, Sisal, Interface, Resistência ao arrancamento, Hornificação

\begin{abstract}
Aiming a reduction in the water absorption capacity of lingo-cellulosic fibers, wetting and drying cycles are usually performed in the industry of paper and cellulose. This procedure stiffens the polymeric structure of the fiber-cells (process known as hornification) resulting in a higher dimensional stability. In the present work it was investigated if the dimensional stability, obtained from the hornification process, can imporove the adhesion of the sisal fiber in a Portland cement matrix. In order to study the fiber-matrix bond adhesion pull-out tests were performed in embedment lengths of $25 \mathrm{~mm}$ and $50 \mathrm{~mm}$. Furthermore, it was investigated the influence of the hornification in the physical behavior (dimensional variation and water absorption), mechanical (behavior under tensile loading) and microstructural (surface modifications of the fiber and changes in the fiber-cell structure). The results indicate a higher dimensional stability, reduction in the water absorption capacity, increase in the tensile strength and strain capacity and reduction in the modulus of elasticity with the hornification. The pull-out load increased which indicates a higher bond strength in the hornified fiber with the cementitious matrix.
\end{abstract}

Keywords: Natural fibers, Sisal fibers, Interface, Bond strength, Hornification 


\section{INTRODUÇÃO}

Na linha de desenvolvimento de materiais reforçados com fibras vegetais, muitas pesquisas vêm sendo desenvolvidas sobre compósitos de matriz cimentícia ou matriz polimérica e resultados promissores têm sido alcançados, mostrando uma melhoria da durabilidade, resistência e ductilidade [1-3]. A opção pelo uso de fibras vegetais como reforço mostra-se benéfica sob vários aspectos, incluindo o da sustentabilidade, uma vez que elas são biodegradáveis e demandam pequena quantidade de energia, quando comparadas com as fibras poliméricas. Devido a sua grande disponibilidade, principalmente em países de clima tropical, as fibras vegetais apresentam baixo custo e têm a grande vantagem de serem renováveis.

A fibra de sisal tem sido uma das fibras mais utilizadas na produção de compósitos à base de cimento, principalmente devido a sua excelente resistência à tração $[4,5]$. No entanto, devido a sua baixa aderência em matrizes à base de cimento, que de acordo com a literatura varia entre 0,32 e $0,72 \mathrm{MPa}$, se faz necessário comprimento de ancoragem maior que $40 \mathrm{~mm}$ para que a fibra possa transferir as tensões internas entre fissuras sem ser arrancada da matriz [6,7]. Dessa forma, a fibra de sisal pode ser utilizada com sucesso em laminados à base de cimento sob a forma de tecidos [8], mas esse aumento do comprimento da fibra torna difícil a produção de compósitos reforçados com grande volume de fibras randomicamente distribuídas. Durante a mistura dos materiais há maior incorporação de ar na mistura, formação de novelos e, consequentemente, redução das propriedades mecânicas do compósito. Associado à baixa adesão química, a alta capacidade de absorção de água das fibras de sisal provoca, ainda, variações em seu volume com a mudança do teor de umidade do compósito, o que resulta em perda de contato físico com a matriz que possui capacidade de absorção e de deformação diferentes das fibras [9].

A melhoria da aderência fibra-matriz e a minimização da capacidade de absorção das fibras vegetais têm sido buscadas pela aplicação de tratamentos, químicos ou físicos, tanto na matriz quanto na fibra. A substituição parcial de cimento por microssílica e escória conferiu aumento no valor da carga adesional em cerca de $24 \%$ [7]. Esse aumento está relacionado com a finura e reatividade da escória e da microssílica que reduziu a porosidade da zona de transição, melhorando a aderência fibra-matriz. $\mathrm{O}$ uso de soluções alcalinas [10] para lavar a superfície de fibras vegetais mostrou ser um método eficaz para remoção de impurezas presentes na superfície das fibras, aumentando a área de contato entre fibra e matriz polimérica, comprovado pelo acréscimo de 73,7\% na resistência à tração do compósito. Tratamento mais simples, com a imersão das fibras em água destilada e a secagem das fibras após este processo, resultou em melhorias na adesão fibramatriz que pode ser observada no aumento de $33 \%$ na resistência a flexão [9]. Quanto à redução da hidrofilicidade, ciclos de molhagem-secagem, empregando água [11] ou ácido acético [12], promoveram menor expansão volumétrica de polpas e fibras de origem natural, bem como modificações em suas propriedades mecânicas. No caso das fibras, ocorreram reduções na resistência à tração e na capacidade de deformação, demonstrando enrijecimento da sua estrutura. Lavagens em água morna levaram ao mesmo resultado, promovendo modificação da camada superficial das fibras de coco, aumentando a área de contato pela exposição das fibrilas e saliências [13].

As aplicações dos tratamentos acima citados mostraram-se eficientes quanto à promoção de modificações na superfície das fibras, porém, ainda faltam informações que apontem de forma mais abrangente as suas devidas melhorias, como a alteração na resistência ao arrancamento em materiais cimentícios. De todo modo, estas análises possuem relevante complexidade, uma vez que algumas fibras vegetais apresentam áreas irregulares e diferentes morfologias [6, 14].

O objetivo do presente trabalho é a melhoria da interface fibra-matriz visando a fabricação de compósitos cimentícios de alto desempenho reforçados com fibras de sisal. Neste estudo, são investigadas as alterações no processo de arrancamento das fibras de sisal em matrizes à base de cimento Portland antes e após ciclos de molhagem e secagem. A investigação baseia-se nas análises físico-mecânicas das fibras, avaliando seu comportamento à tração direta, capacidade de absorção de água assim como análises em microescala, avaliando modificações na seção transversal das fibras.

\section{PROGRAMA EXPERIMENTAL}

\subsection{Materiais}

Foram utilizadas fibras de sisal provenientes do Município de Valente, Bahia, obtidas com comprimento variando de $90 \mathrm{~cm}$ a $100 \mathrm{~cm}$. Inicialmente as fibras foram lavadas em água quente, para retirada de resíduos superficiais, como mucilagens, oriundos do processo de extração. 
O procedimento utilizado para o tratamento das fibras na presente pesquisa foi baseado no procedimento desenvolvido por Claramunt et al. [11]. O processo consistiu na imersão das fibras em água $\left(\mathrm{T} \sim 23^{\circ} \mathrm{C}\right)$ e sua retirada para secagem após saturação (Figura 1(a)). As fibras de sisal foram colocadas em um recipiente com água onde permaneceram por 3 horas, tempo suficiente para atingir a saturação. Em seguida, iniciou-se a secagem em estufa a uma temperatura de $80^{\circ} \mathrm{C}$. A estufa utilizada é equipada com um forno com controle eletrônico de temperatura, Flyeyer modelo FE50RP (ver Figura 1(b)), e interligado a uma balança, externa, digital Marte, com precisão de 0,01g (Figura 1(c)). A estufa foi programada para atingir $80^{\circ} \mathrm{C}$ a uma taxa de aquecimento de $1^{\circ} \mathrm{C} / \mathrm{min}$ permanecendo nesta temperatura por 16 horas. Após as 16 horas de secagem a estufa foi resfriada até atingir a temperatura de $23^{\circ} \mathrm{C}$ a fim de se evitar um possível choque térmico nas fibras. Todo este procedimento corresponde a um ciclo, e foi repetido dez vezes.
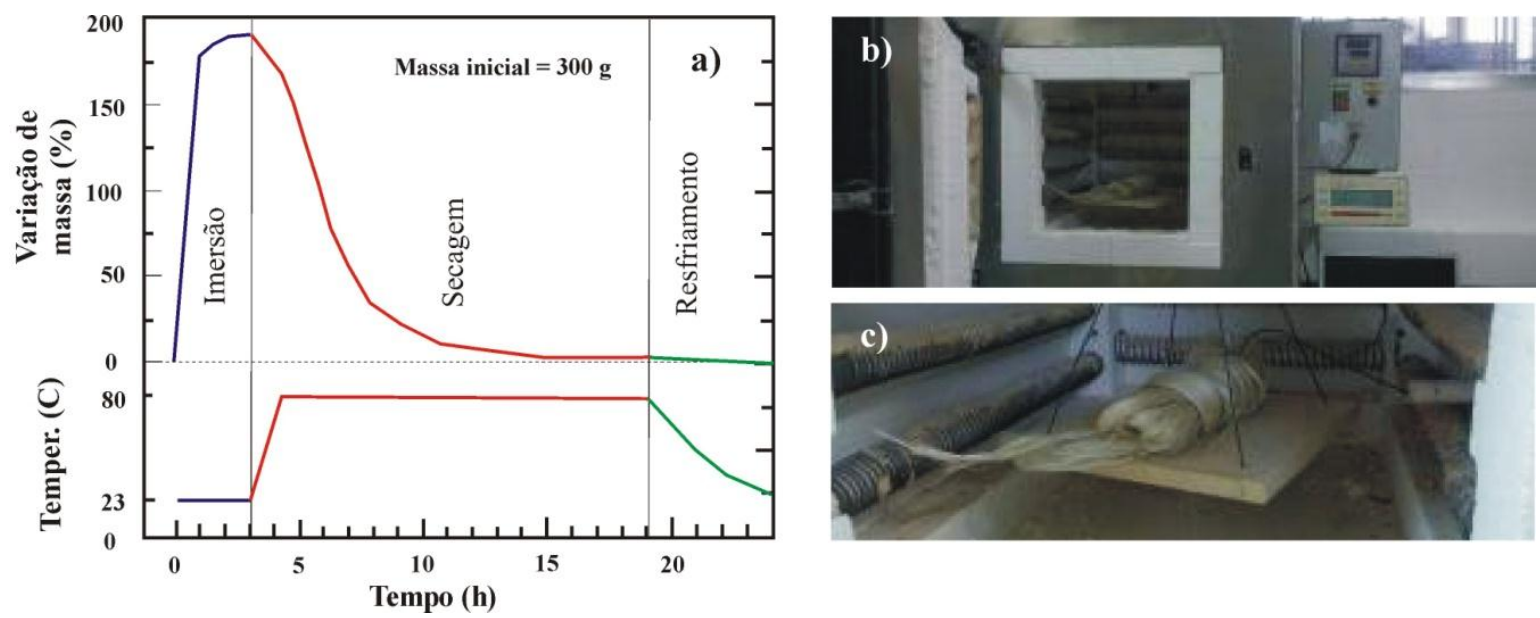

Figura 1: Ciclo de molhagem e secagem das fibras de sisal: (a) curva de absorção e dessorção de água, (b) estufa utilizada nos ciclos de secagem e (c) balança.

Para avaliação da aderência fibra-matriz foi moldada uma matriz de argamassa, no traço 1:0,5:0,4 (aglomerante:areia:fator água/cimento), em massa. Como aglomerante foi utilizado $30 \%$ de cimento Portland CP II F-32, 30\% de metacaolinita e 40\% de cinza volante. Tal proporção de metacaolinita tem como objetivo a garantia da durabilidade da fibra, conforme indicado em pesquisa anterior [15]. A presença da cinza volante visa, sobretudo, garantir maior trabalhabilidade que, dentro do contexto dos compósitos de alto desempenho, é uma propriedade desejável, pois garante melhor homogeneização das fibras [16]. A areia utilizada foi beneficiada para obtenção de um diâmetro máximo de $840 \mu \mathrm{m}$. Também foi utilizado o Superplastificante Glenium 51 (tipo PA), com teor de sólidos de $31,20 \%$, na proporção de $0,95 \%$ do total de finos na mistura, valor referente a $36 \mathrm{l} / \mathrm{m}^{3}$ e aditivo modificador de viscosidade, de nome comercial Rheomac UW 410, fabricado pela empresa BASF, na dosagem de $0,8 \mathrm{~kg} / \mathrm{m}^{3}$, de para evitar segregação da mistura durante a moldagem. A matriz utilizada no presente trabalho apresentou um valor de espalhamento de $450 \mathrm{~mm}$, de acordo com a NBR 13276/05[17], e resistência à compressão aos 28 dias de $31 \mathrm{MPa}$, de acordo com a NBR 7215/96 [18].

As misturas foram produzidas em sala climatizada a $21 \pm 1^{\circ} \mathrm{C}$, utilizando um misturador de bancada com capacidade de $5 \mathrm{dm}^{3}$. O processo de produção foi desenvolvido de acordo as seguintes etapas: a) mistura da água + superplastificante por 30 segundos na argamassadeira; b) mistura prévia (em sacos) dos materiais finos (1 minuto) e lançamento na argamassadeira (2 minutos); c) mistura dos materiais durante 2 minutos em velocidade baixa (166 RPM); d) parada de 30 segundos para retirada de material retido na argamassadeira; e) mistura por mais 2 minutos em velocidade baixa; $f$ ) adição de VMA; f) mistura por mais 2 minutos em velocidade baixa. A argamassa foi colocada em sacos plásticos para lançamento nos moldes, como mostra a Figura $2 \mathrm{a}$.

Para moldagem dos corpos de prova do ensaio de arrancamento foram desenvolvidas duas placas prismáticas de acrílico com pontos de encaixe para moldes de PVC, e furos no centro, para garantir o alinhamento das fibras (Figura 2b). Após o preenchimento do molde com a matriz, a tampa superior foi encaixada e a fibra levemente esticada para obter um melhor alinhamento. Após 24h, os corpos de prova foram desmoldados e dispostos em uma câmara úmida para ensaio de arrancamento. 


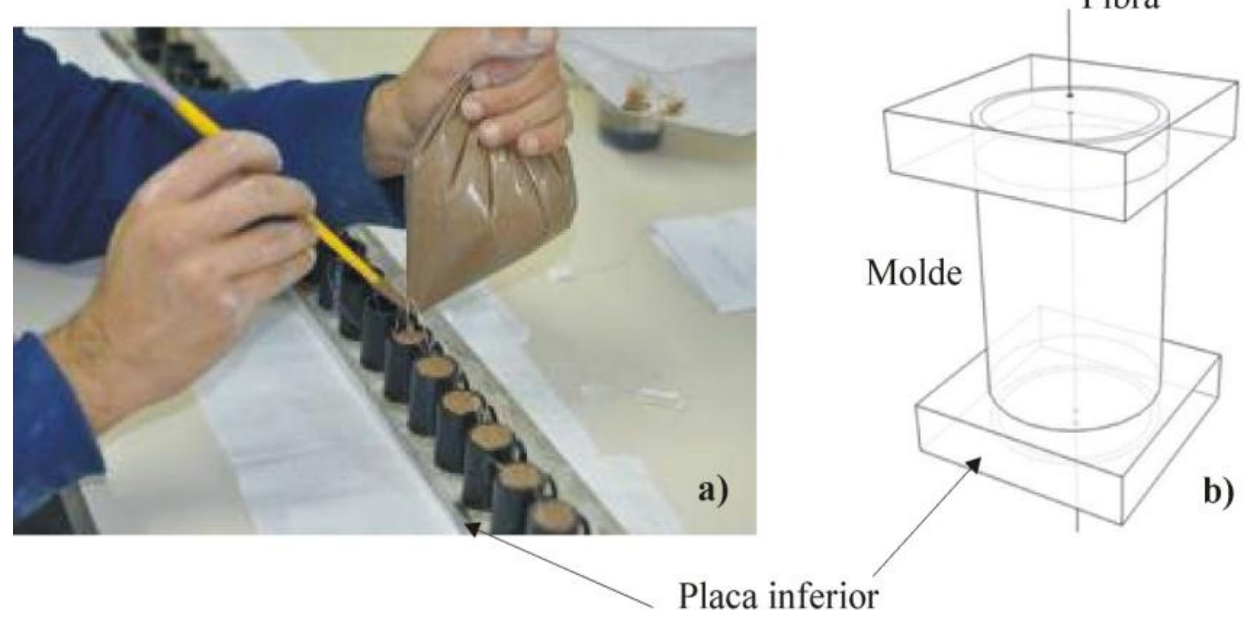

Figura 2: Moldagem dos corpos de prova para ensaio de arrancamento: (a) preenchimento dos moldes com a matriz e (b) posicionamento da fibra no molde.

\subsection{Testes Físicos e Mecânicos}

\subsubsection{Absorção e Variação dimensional}

O índice de absorção de água (IA) das fibras de sisal tratadas e não tratadas foi calculado pela equação (1):

\section{IA $=$ Pest-Pum/Pest}

onde $P_{\text {est }}$ representa o peso da fibra seca em estufa e $P_{u m}$ o peso úmido (após saturação).

Para a análise da variação dimensional das fibras, foi adotado o seguinte procedimento: antes do processo de ciclagem, vinte e duas fibras selecionadas sofreram um corte longitudinal. Foram então definidos dois diâmetros, $\mathrm{D}_{1}$ e $\mathrm{D}_{2}$, que, antes da ciclagem eram iguais. Uma parte da fibra foi submetida a dez ciclos de molhagem e secagem enquanto a outra permaneceu em ambiente natural.

Para avaliação da influência da ciclagem na variação dimensional, foram realizadas micrografias das fibras em estado seco e após os ciclos. As áreas da seção transversal das fibras foram então obtidas e comparadas. As micrografias forma obtidas por microscopia eletrônica de varredura (MEV), utilizando o detector de elétrons secundários no equipamento JEOL JSM-6460. As medições da área de contorno da seção transversal da fibra foram feitas com o auxílio do software ImageJ. As fibras foram previamente recobertas com aproximadamente $20 \mathrm{~nm}$ de ouro para se tornarem condutoras e mais adequadas à análise ao MEV. O MEV foi operado sob uma tensão de aceleração de $20 \mathrm{kV}$ e uma distância de trabalho de aproximadamente $30 \mathrm{~mm}$.

\subsubsection{Ensaio de tração direta}

O ensaio foi realizado em uma máquina de ensaios eletromecânica modelo Shimadzu AG-X com célula de carga de $1 \mathrm{kN}$, e controle de deslocamento de $0,1 \mathrm{~mm} / \mathrm{min}$ (ver Figura 3 a). Os ensaios foram realizados de acordo com a norma ASTM C1557. As fibras com comprimento nominal de $50 \mathrm{~mm}$ foram coladas a um molde de papel, para melhor alinhamento na máquina e maior aderência às garras do eixo superior e inferior (ver Figura 3 (b)). Para o cálculo da resistência à tração foram ensaiadas 15 fibras de $50 \mathrm{~mm}$ de comprimento cujos diâmetros foram medidos por microscopia eletrônica de varredura. 

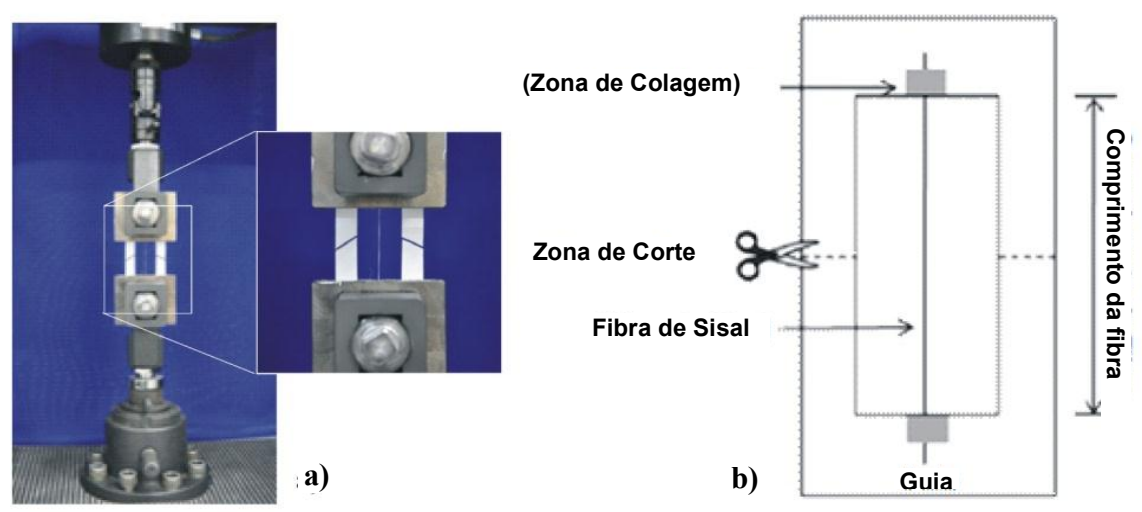

Figura 3: Ensaio de tração direta na fibra de sisal: (a) arranjo do ensaio e detalhe das garras e (b) molde de papel para fixação da fibra [19].

\subsubsection{Ensaio de arrancamento}

A influência do tratamento da fibra sobre a aderência da fibra à matriz foi avaliada pelo ensaio de arrancamento. Foram utilizados dois comprimentos de embebimento: $25 \mathrm{~mm}$ e $50 \mathrm{~mm}$.

O ensaio foi realizado em uma máquina de ensaios eletromecânica modelo Shimadzu AGX, com célula de carga de $1 \mathrm{kN}$, e velocidade de deslocamento de $0,1 \mathrm{~mm} / \mathrm{min}$. As amostras foram presas nas garras da máquina de ensaio através de um sistema plástico birrotulado, como mostra a Figura 4. Foram ensaiados 32 corpos de prova para cada comprimento de ancoragem após 7 dias de cura em câmara úmida e um dia de secagem nas seguintes condições de temperatura e umidade: $\mathrm{T}: 23^{\circ} \mathrm{C} \pm 1^{\circ} \mathrm{C}$ e UR $(\%): 43 \% \pm 3 \%$, para retirada do excesso da água presente na fibra.

a) Configuração

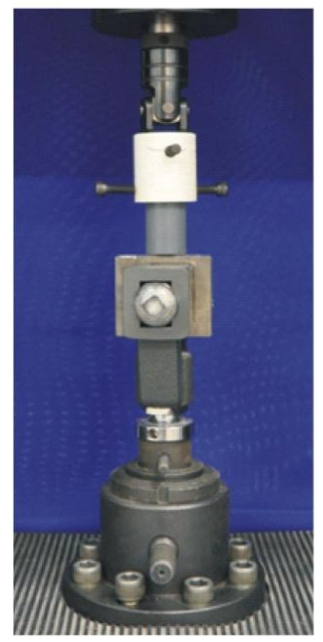

b) Sistema bi-rotulado

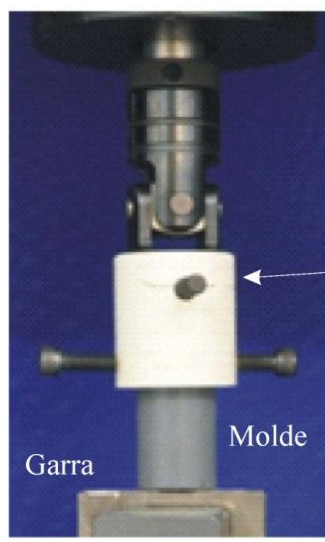

c) Arrancamento da fibra

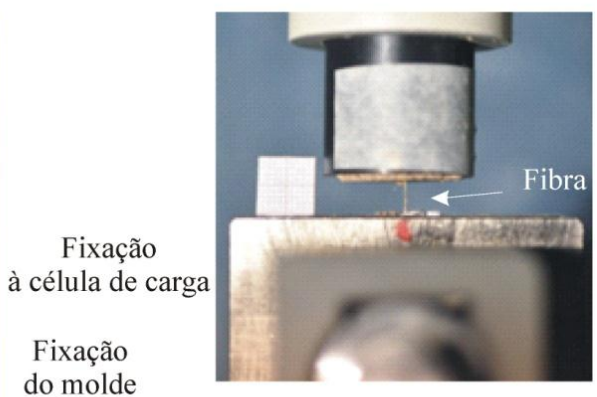

do molde

Figura 4: Ensaio de arrancamento: a) configuração; b) detalhe do sistema de fixação do amostra; c) detalhe da fibra presa à garra

A partir da carga de arrancamento P, obtida experimentalmente, é possível calcular a tensão de aderência média entre a fibra e a matriz utilizando a equação (2):

$$
\tau=\frac{P}{2 \pi r l}
$$

onde $l$ é o comprimento de embebimento da fibra e $r$ é o raio da fibra calculado através de imagem obtida por microscopia eletrônica de varredura. 


\section{RESULTADOS E DISCUSSÕES}

\subsection{Análise da fibra}

Os ciclos de molhagem e secagem realizados nas fibras de sisal resultaram em uma diminuição do índice de absorção de água (IA) das fibras como mostra a Figura (5).

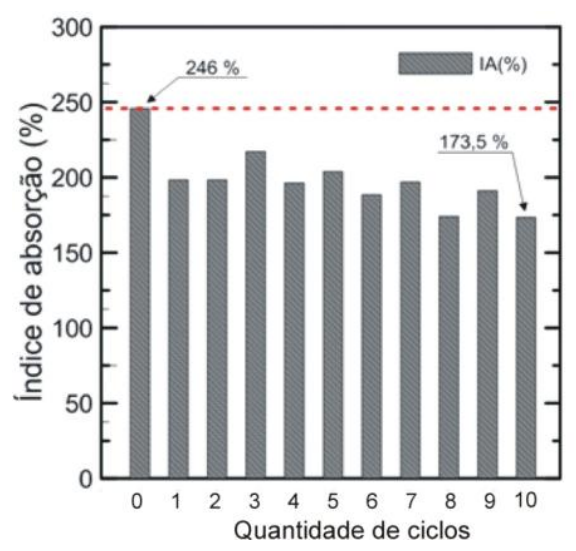

Figura 5: Variação do índice de absorção de água (IA) das fibras de sisal após os ciclos de molhagem e secagem.

É possível notar que, após 10 ciclos, a variação no índice de absorção das fibras é de cerca de $30 \%$. De forma semelhante, Brancato [20] após aplicar tratamentos de ciclagens em fibras de celulose, observou diminuições de até $50 \%$ na capacidade de retenção de água das fibras.

Este comportamento pode ser explicado pelo enrijecimento da estrutura polimérica das fibrocélulas do sisal que ocorre durante o processo de molhagem e secagem (processo conhecido como hornificação). De acordo com Diniz et al. [21], as cadeias de polissacarídeos da celulose são arranjadas de forma mais apertada com a remoção de água durante a secagem e com isso as microfibrilas se juntam, no estado seco, como resultado do maior empacotamento. Os vazios capilares da fibra são progressivamente fechados com a secagem e não conseguem mais ser completamente reabertos com a reumidificaçao.

De fato, observando a Figura 6 a e Figura 6 c, que mostra a seção transversal das fibras e o detalhe dos lumens Figura 6 b e Figura 6 d, verifica-se um maior empacotamento das fibrocélulas e uma redução do lúmen após submissão ao tratamento, o que, consequentemente, reduz a capacidade de absorção de água da fibra.
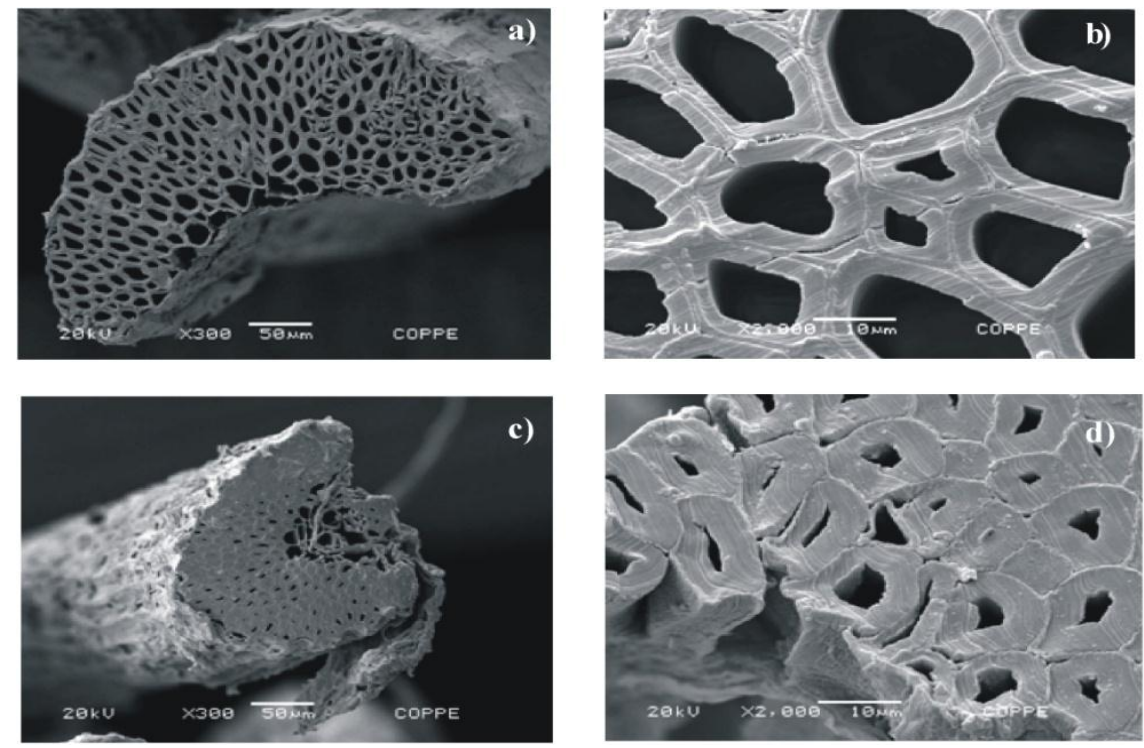

Figura 6: Seção transversal das fibras mostrando detalhe das fibrocélulas: (a-b) sem tratamento e (c-d) tratadas. 
Uma consequência direta da redução da absorção é a redução da variação dimensional da fibra entre o estado seco e saturado. Na Figura 7 são apresentadas as variações da área de seção de transversal de 30 fibras de sisal quando submetidas à saturação completa e posterior secagem em estufa. Retas paralelas tracejadas indicam a variação média. Para as 15 fibras naturais (sem tratamento), a área média das fibras secas foi de $0,027 \mathrm{~mm}^{2}$ e das fibras saturadas de $0,037 \mathrm{~mm}^{2}$, o que corresponde a uma diferença de $27 \%$. Após a hornificação, as 15 fibras tratadas apresentaram seção média no estado seco de $0,029 \mathrm{~mm}^{2}$ e após saturação de 0,035 $\mathrm{mm}^{2}$, ou seja, diferença de $17 \%$. Observa-se que, com a hornificação, ocorre uma redução importante na variação da seção transversal da fibra, quando se varia o estado de umidade da mesma. Baseado em estudos anteriores, Diniz et al. [21] confirmam que após vários ciclos de molhagem e secagem, há redução na retenção de água da fibra vegetal e não se verifica variação na largura da fibra, isso porque o processo de secagem das fibras causa uma significante redução dos grandes poros e uma redução da área superficial.

Além da variação nas propriedades físicas das fibras de sisal, verifica-se que a hornificação, causada pelos ciclos de molhagem e secagem, modificou o comportamento tensão-deformação das fibras sob tração direta, como mostra a Figura 8, tornando a fibra mais resistente e mais deformável.

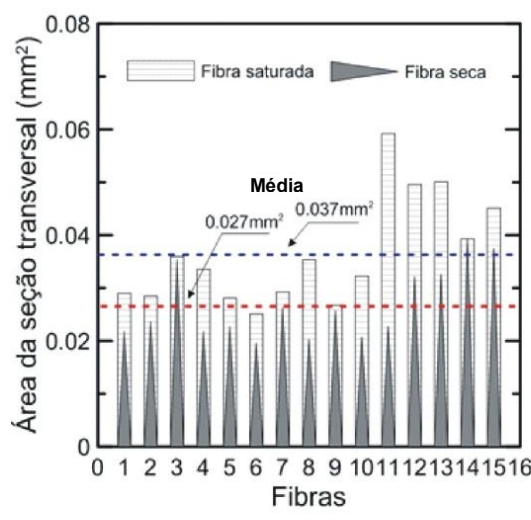

a) fibra sem tratamento

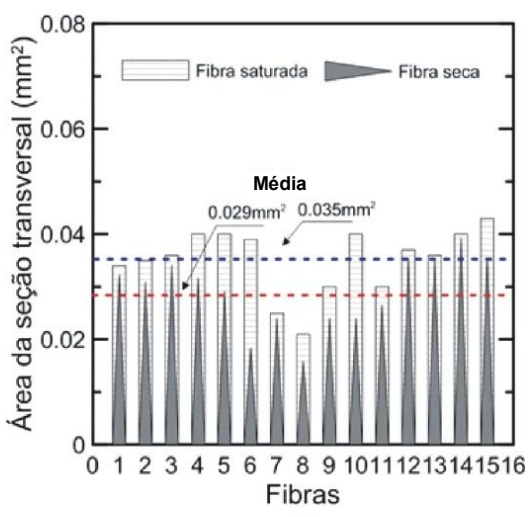

b) fibra tratada

Figura 7: Variação volumétrica das fibras devido à variação de umidade.

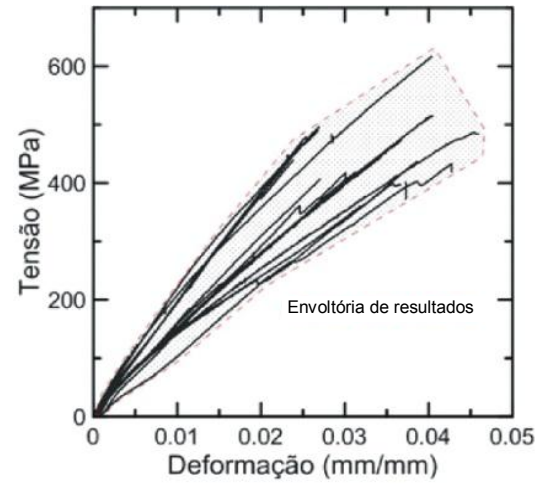

a) fibra sem tratamento

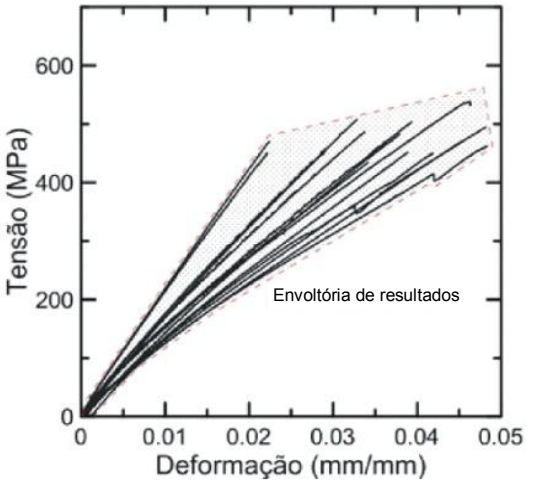

b) fibra tratada

Figura 8: Influência dos ciclos de molhagem e secagem no comportamento sob tração direta.

A Tabela 1 apresenta os resultados do ensaio de tração direta, com desvio padrão entre parênteses. Um estudo comparativo das médias, utilizando o Teste de Tukey, demonstrou que, para intervalo de 5\% de confiança, elas são estatisticamente diferentes. 
Tabela 1: Resultado dos ensaios de tração direta.

\begin{tabular}{c|c|c|c}
\hline TRATAMENTO & $\begin{array}{c}\text { TENSÃO DE RUPTURA } \\
\mathbf{( M P a )}\end{array}$ & $\begin{array}{c}\text { DEFORMAÇÃo DE } \\
\text { RUPTURA } \\
\mathbf{( m m / m m}\end{array}$ & $\begin{array}{c}\text { MÓDULO DE ELASTICIDADE } \\
\mathbf{( G P a )}\end{array}$ \\
\hline Sem tratamentos & $447,20(23,90)$ & $0,0303(0,0058)$ & $19279,88(1361,14)$ \\
\hline Tratada & $470,25(16,56)$ & $0,0431(0,0061)$ & $17602,69(1225,25)$ \\
\hline
\end{tabular}

Verifica-se que os valores encontrados para fibra natural (sem tratamento) encontram-se dentro da faixa encontrada por outros pesquisadores [22]. Após o tratamento, no entanto, as fibras apresentaram aumento de $5,2 \%$ e $38,7 \%$, para tensão de ruptura e deformação de ruptura, respectivamente, e redução de $8,7 \%$ no módulo de elasticidade. $\mathrm{O}$ aumento da resistência à tração está associado à consideração de uma seção transversal mais densa, visto que o processo de ciclagem reduziu os lúmens da fibra, como mostra a comparação entre as Figuras 6 b e 6 d.

\subsection{Aderência fibra-matriz}

A variação dimensional devido à mudança na condição de umidade da fibra vegetal é uma das responsáveis pela perda de aderência entre a matriz e a fibra. Durante a moldagem do compósito, a fibra de sisal absorve água da mistura e aumenta o seu diâmetro. Em condições de uso, o compósito já no estado endurecido entra em equilíbrio com a umidade do ambiente e a perda de água da fibra resulta em uma variação na seção transversal, como mostra a Figura 7. Como a espessura da zona de transição sisal-matriz é da ordem de $200 \mu \mathrm{m}$ [23] acredita-se que essa variação dimensional enfraqueça a zona interfacial e reduza a capacidade de transmissão de esforços. Dessa forma, espera-se que a redução da variação da seção da fibra devida à hornificação melhore a aderência fibra-matriz.

Na Figura 9 são apresentadas curvas típicas força-deslizamento obtidas no ensaio de arrancamento. As propriedades calculadas são apresentadas na Tabela 2. Entre parênteses é informado o desvio padrão. $\mathrm{O}$ valor de rigidez apresentado é calculado como a relação entre a carga máxima e o deslizamento correspondente.
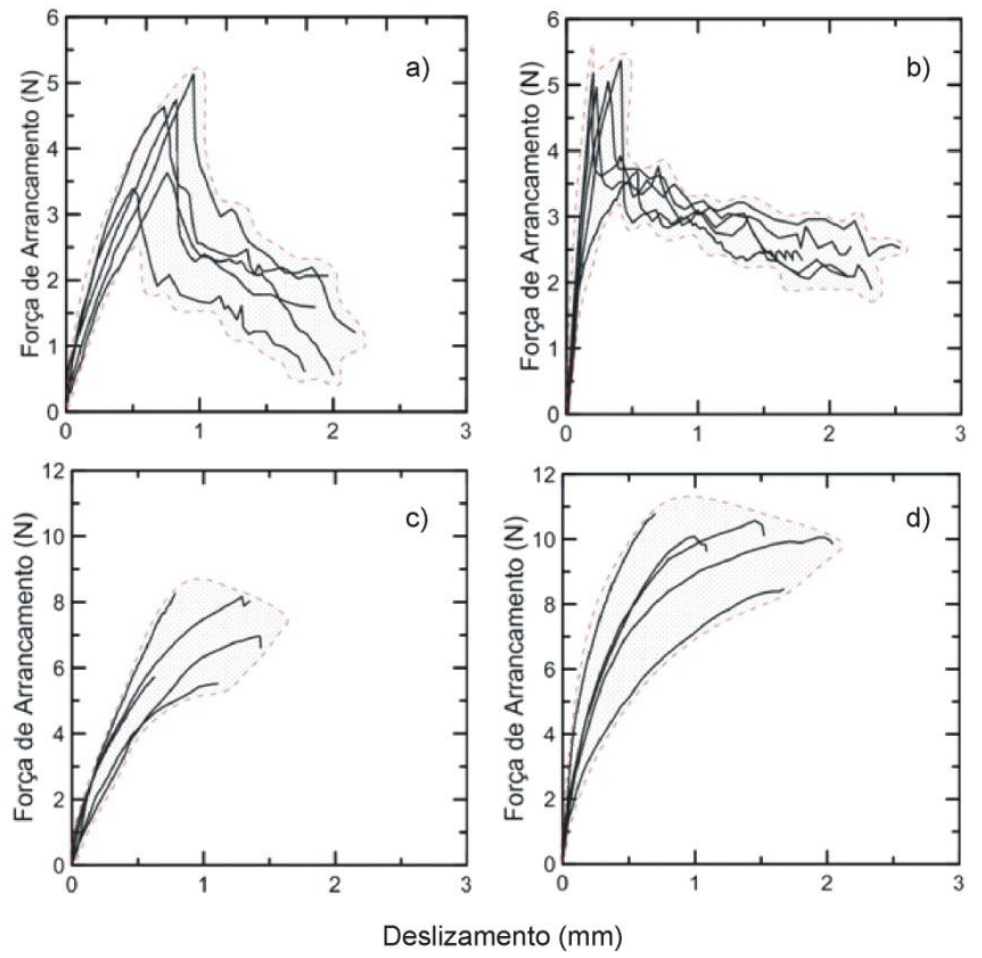

Figura 9: Influência da hornificação e comprimento na força de arrancamento das fibras de sisal: (a) $25 \mathrm{~mm}$ natural, (b) $25 \mathrm{~mm}$ tratada, (c) $50 \mathrm{~mm}$ natural e (d) $50 \mathrm{~mm}$ tratada. 


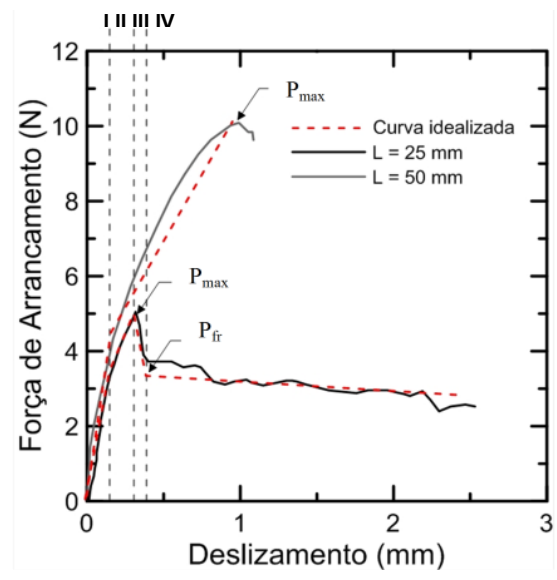

Figura 10: Comportamento típico força-deslizamento das curvas de arrancamento obtidas.

As curvas força-deslizamento obtidas no ensaio de arrancamento podem ser idealmente esquematizadas de acordo com a Figura 10. Na curva para comprimento de fibra L $=25 \mathrm{~mm}$ quatro regiões são identificadas: a primeira (I) correspondente à zona linear elástica, na qual a aderência é admitida perfeita. Na região II observa-se a perda de linearidade, definida como ponto inicial de descolamento entre a fibra e matriz. Este ponto é referente à decoesão interfacial, que se propaga estavelmente até que a carga atinja o pico, que é o ponto em que se atinge o maior valor de força de arrancamento $\left(\mathrm{P}_{\max }\right)$. Na região III, após a carga de pico, observa-se uma diminuição da rigidez da curva que corresponde ao estágio em que a decoesão é total, ou seja, toda a fibra está descolada da matriz. Inicia-se a região IV, indicada pela carga $\mathrm{P}_{\mathrm{fr}}$, que corresponde, de fato, ao arrancamento da fibra. Verifica-se que, a depender do comprimento da fibra imerso na matriz, as regiões III e IV podem não acontecer devido à ruptura da fibra, como mostram as curvas para $\mathrm{L}=50 \mathrm{~mm}$.

Tabela 2: Resultados do ensaio de arrancamento.

\begin{tabular}{c|c|c|c|c|c|c}
\hline $\begin{array}{c}\mathbf{L} \\
(\mathbf{m m})\end{array}$ & TRATAMENTO & $\begin{array}{c}\text { Pmax } \\
\mathbf{( N )}\end{array}$ & $\begin{array}{c}\text { Tmax } \\
\mathbf{( M P a})\end{array}$ & $\begin{array}{c}\mathbf{P f r} \\
\mathbf{( N )}\end{array}$ & $\begin{array}{c}\text { Tfr } \\
(\mathbf{M P a})\end{array}$ & $\begin{array}{c}\text { RIGIDEZ } \\
\mathbf{( N / m m}\end{array}$ \\
\hline \multirow{2}{*}{25} & $\begin{array}{c}\text { Sem } \\
\text { tratamento }\end{array}$ & $3,73(1,02)$ & $0,30(0,08)$ & $2,56(0,72)$ & $0,18(0,04)$ & $9,31(4,39)$ \\
\cline { 2 - 7 } & Tratada & $4,53(1,07)$ & $0,42(0,08)$ & $3,88(0,77)$ & $0,27(0,03)$ & $20,60(6,37)$ \\
\hline \multirow{2}{*}{50} & $\begin{array}{c}\text { Sem } \\
\text { tratamento }\end{array}$ & $6,35(1,15)$ & $0,32(0,09)$ & - & - & $33,83(16,04)$ \\
\cline { 2 - 7 } & Tratada & $8,46(2,73)$ & $0,43(0,07)$ & - & - & $47,29(13,15)$ \\
\hline
\end{tabular}

Os resultados dos ensaios de arrancamento apontam que a hornificação proporcionou um aumento na capacidade de ancoragem da fibra à matriz. Para fibras com comprimento de embebimento $\mathrm{L}=25 \mathrm{~mm}$, esta melhoria foi observada na tensão máxima de arrancamento, com aumento de $40 \%$, e na tensão friccional, com aumento de 50\%. As fibras com $\mathrm{L}=50 \mathrm{~mm}$ apresentaram ruptura antes de serem arrancadas da matriz. Para estas fibras verificou-se um aumento de $34,4 \%$ na tensão máxima de arrancamento devido à hornificação.

Avaliando a força de arrancamento, verifica-se que o aumento do comprimento de embebimento, de $25 \mathrm{~mm}$ para $50 \mathrm{~mm}$, conferiu melhorias na força de arrancamento máxima, tanto nas fibras sem tratamento, que aumentou de 3,73 para $6,35 \mathrm{~N}$, como nas fibras tratadas, que aumentou de 4,53 para 8,46 N, respectivamente. Em sua pesquisa, Silva et al. [6] observou um acréscimo da carga máxima em média de 2,2 a 8,07 N, com comprimentos de 10 a $40 \mathrm{~mm}$, respectivamente.

Os valores de Rigidez, apresentados na Tabela 2, demonstram como a ciclagem das fibras permitiu que se formasse uma zona de interface fibra-matriz mais densa. Este aumento de rigidez foi de foi de $121 \%$ para $\mathrm{L}=25 \mathrm{~mm}$ e $39,8 \%$ para $\mathrm{L}=50 \mathrm{~mm}$. Com a hornificação das fibras e a redução da sua absorção de água, é esperado que a zona de interface fibra-matriz torne-se tão densa quanto a matriz, com menor espessu- 
ra e com pequena ocorrência de portlandita, como já identificado em compósitos a base de cimento reforçados com fibras pouco permeáveis, como asbesto e polipropileno [23].

\section{CONCLUSÕES}

Com os resultados apresentados pode-se chegar as seguintes conclusões:

- As fibras de sisal após serem submetidas a 10 ciclos de molhagem e secagem sofreram um processo de hornificação que resultou na diminuição da capacidade de absorção de água das fibras bem como na redução das variações dimensionais da seção transversal decorrentes da variação de umidade;

- Após a hornificação, a fibra de sisal apresentou, sob tração direta, um aumento na capacidade de deformação e na tensão de ruptura, porém, com redução em seu módulo de elasticidade;

- No ensaio de arrancamento, foi observado um aumento de até $40 \%$ na tensão de aderência máxima e de $50 \%$ da tensão friccional, com a hornificação;

- A hornificação mostrou-se eficiente, proporcionando uma valorização à fibra de sisal, possibilitando sua utilização para o desenvolvimento de compósitos com melhores comportamentos mecânicos.

\section{AGRADECIMENTOS}

Os autores agradecem à Fundação de Amparo a Pesquisa do Estado da Bahia (FAPESB) e ao Conselho Nacional de Desenvolvimento Cientifico e Tecnológico (CNPq: 558633/2010-2) pelo apoio.

\section{BIBLIOGRAFIA}

[1] MELO FILHO, J.A., "Desenvolvimento e caracterização de laminados cimentíceos reforçados com fibras longas de sisal”, Tese de D.Sc. em Engenharia Civil, COPPE/UFRJ, Rio de Janeiro, Brasil, 2012.

[2] RAMÍREZ, M.G.L., MUNIZ, G.I.B., SATYANARAYANA, K.G., et al., "Preparation and characterization of biodegradable composites based on Brazilian cassava starch, corn starch and green coconut fibers", Revista Matéria, v. 15, n. 2, pp. 370-377, 2010.

[3] TOLEDO FILHO, R.D., SCRIVENER, S., ENGLAND, G.L., et al., "Durability of alkali-sensitive sisal and conconut fibres in cement mortar composites", Cement \& Concrete Composites, v. 22, pp. 127-143, 2000 .

[4] SILVA, F.A., CHAWLA, N., TOLEDO FILHO, R.D. "Mechanical behavior of natural sisal fibers", Journal of Biobased Materials and Bioenergy, v. 4, n. 2, pp. 106-113, 2010.

[5] INACIO, W.P., LOPES, F.P.D., MONTEIRO, S.N., "Diameter dependence of tensile strength by Weibull analysis: Part III sisal fiber”, Revista Matéria, v. 15, n. 2, pp. 176-182, 2010.

[6] SILVA, F.A., MOBASHER, B., SORANAKOM, C., et al. "Effect of fiber shape and morphology on interfacial bond and cracking behaviors of sisal fiber cement based composites", Cement and Concrete Composites, v. 33, pp. 814-823, 2011.

[7] TOLÊDO FILHO, R.D., Materiais compósitos reforçados com fibras naturais: caracterização experimental. Tese de D.Sc. em Engenharia Civil, DEC/PUC-Rio, Rio de Janeiro, Brasil, 1997.

[8] TOLEDO FILHO, R.D., SILVA, F.A., FAIRBAIRN, E.M.R., et al., "Durability of compression molded sisal fiber reinforced mortar laminates”, Construction \& Building Materials, v. 23, pp. 2409-2420, 2009.

[9] LI, Y., HU, C., YU, Y., "Interfacial studies of sisal fiber reinforced high density polyethylene (HDPE) composites", Composites Part A: Applied Science and Manufacturing, v. 39, n. 4, pp. 570-578, 2008.

[10] ANGRIZANI, C.A.B., VIEIRA, A.J., ZATTERA, E., et al., "Influência do comprimento da fibra de sisal e do seu tratamento químico nas propriedades de compósitos com poliéster", In: CBECIMat, Congresso Brasileiro de Engenharia e Ciência dos Materiais, Foz do Iguaçu, PR, Brasil, 2006

[11] CLARAMUNT, J., ARDANUY, M., GARCIA-HORTAL, J.A., "Effect of drying and rewetting cycles on the structure and physicochemical characteristics of softwood fibres for reinforcement of cementitious composites", Carbohydrate Polymers, v. 79, pp. 200-205, 2010.

[12] LOPES, F.F.M., ARAUJO, G.T, NASCIMENTO, J.W.B., et al., "Estudo dos efeitos da acetilação em fibras de sisal”, Revista Brasileira de Engenharia Agrícola e Ambiental, v. 14, n. 7, pp. 783-788, 2010. 
[13] SELVAM, P.V.P., SANTIAGO, B.H., "Tratamento superficial da fibra do coco: estudo de caso baseado numa alternativa econômica para fabricação de materiais compósitos”, Revista Analytica, n. 26, pp. 783-788, 2007.

[14] MONTEIRO, S.N., D’ALMEIDA, J.R.M., "Ensaios de Pullout em fibras lignocelulósicas -uma metodologia de análise”. Revista Matéria, v. 11, n. 3, pp. 189-196, 2006.

[15] LIMA, P.R.L., TOLEDO FILHO, R.D., "Uso de metacaulinita para incremento da durabilidade de compósitos à base de cimento reforçados com fibras de sisal”, Ambiente Construído, v. 8, n. 4, pp. 7-19, 2008.

[16] FERREIRA, S., "Influência da hornificação na aderência fibra-matriz e no comportamento mecânico de compósitos cimentícios reforçados com fibras curtas de sisal”, Tese de M.Sc. em Engenharia Civil e Ambiental, UEFS, Feira de Santana, Brasil, 2012.

[17] ASSOCIAÇÃO BRASILEIRA DE NORMAS TÉCNICAS, NBR 13276: argamassa para assentamento e revestimento de paredes e tetos: preparo da mistura e determinação do índice de consistência, Rio de Janeiro, 2005. 3p.

[18] ASSOCIAÇÃO BRASILEIRA DE NORMAS TÉCNICAS, NBR 7215: cimento Portland: determinação da resistência à compressão, 1996. 8p.

[19] KIM, J.T. NETRAVALI, A.N., "Mercerization of sisal fibers: effect of tension on mechanical propertiesof sisal fiber and fiber-reinforced composites", Composites Part A: Applied Science and Manufacturing, v. 41, n. 9, pp. 1245-1252, 2010.

[20] BRANCATO, A.A. "Effect of progressive recycling on cellulose fiber surface properties". Thesis of D.Sc, - School of Chemical and Biomolecular Engineering, Georgia Institute of Technology, December, 2008.

[21] DINIZ, J.M.B.F., Gil, M.H., CASTRO, J.A.A.M. "Hornification-its origin and interpretation in wood pulps", Wood Science Technology, v. 37, pp. 489-494, 2004.

[22] LI, Y., MAI, Y-W, YE, L., "Sisal fibre and its composites: a review of recent developments", Composites Science and Technology, v. 60, pp. 2037-2055, 2000.

[23] SAVASTANO JR, H., AGOPYAN, V., "Transition zone studies of vegetable fibre-cement paste composites", Cement and Concrete Composites, v. 21, pp. 49-57, 1999.

\section{$\underline{\text { Errata }}$}

Este artigo sofreu a seguinte alteração no dia 22.11.12

Na página 1027, na equação 1, onde se via o espaço em branco, lê-se:

$$
\mathrm{IA}=\text { Pest-Pum/Pest }
$$

Este artigo também sofreu a seguinte alteração:

Na página 1030, as figuras 7 e 8 estavam trocadas, ou seja, onde se lia figura 7 leia-se figura 8 e vice-versa. 